\title{
CADEIA LOGÍSTICA DA INDÚSTRIA DE BIOCOMBUSTÍVEIS: UMA ABORDAGEM METASSÍNTESE
}

\author{
Juliana Behling da Silva \\ Universidade Federal do Rio Grande \\ Av. Itália, s/n - Km 8 - Carreiros, Rio Grande - RS \\ jubehling@gmail.com \\ Diogo Garcia Storino \\ Universidade Federal do Rio Grande \\ Av. Itália, s/n - Km 8 - Carreiros, Rio Grande - RS \\ diogo.storino@hotmail.com \\ Ticiani Chaves Gonçalves \\ Universidade Federal do Rio Grande \\ Av. Itália, s/n - Km 8 - Carreiros, Rio Grande - RS \\ ticiani.chagon@gmail.com \\ André Andrade Longaray \\ Universidade Federal do Rio Grande \\ Av. Itália, s/n - Km 8 - Carreiros, Rio Grande - RS \\ andrelongaray@gmail.com \\ Paulo Roberto da Silva Munhoz \\ Universidade Federal do Rio Grande \\ Av. Itália, s/n - Km 8 - Carreiros, Rio Grande - RS \\ paulorsmunhoz@gmail.com
}

\section{RESUMO}

Este trabalho tem como proposta mapear o estado da arte sobre a temática da logística no âmbito da indústria de biocombustível. Na metodologia é classificada quanto propósito por pesquisa-diagnóstico de caráter quali-quantitativo, com delineamento descritivo, tendo o método de coleta de dados em bases de pesquisa e uma análise bibliométrica. O campo empírico constitui-se de 115 artigos, estes foram analisados através de uma revisão sistemática com a área de investigação sendo uma metassíntese qualitativa. Foi realizado um levantamento de três parâmetros para posterior discussão: modal de transporte, geográfico e produção. Este estudo buscou contribuir para reflexão sobre esses elementos da cadeia logística da indústria dos bicombustíveis, de forma a propor futuros estudos embasados no cenário atual.

Palavra-chave: Biocombustíveis; Cadeia logística; Cadeia de suprimentos; Combustível renovável; Combustível alternativo. 


\begin{abstract}
This paper aims to map the state of the art on the theme of logistics within the biofuel industry. The methodology is classified as purpose by qualitative-quantitative research-diagnostic, with descriptive design, having the method of data collection in research bases and a bibliometric analysis. The empirical field consists of 115 articles, these were analyzed through a systematic review with the research area being a qualitative metasynthesis. A survey of three parameters was conducted for further discussion: transport modal, geographical and production. This study sought to contribute to reflection on these elements of the biofuels industry logistics chain, in order to propose future studies based on the current scenario.
\end{abstract}

Keywords: Biofuels; Logistic chain; Supply chain; Renewable fuel; Alternative fuel.

\title{
Como Citar:
}

SILVA, Juliana Behling da; STORINO, Diogo Garcia; GONÇALVES, Ticiani Chaves; LONGARAY, André Andrade; MUNHOZ, Paulo Roberto da Silva; Cadeia logística da indústria de biocombustíveis: uma abordagem metassíntese. In: SIMPÓSIO DE PESQUISA OPERACIONAL E LOGÍSTICA DA MARINHA, 19., 2019, Rio de Janeiro, RJ. Anais [...]. Rio de Janeiro: Centro de Análises de Sistemas Navais, 2019.

\section{INTRODUÇÃO}

Desde a década de 70, há uma crescente busca por soluções alternativas ao consumo de petróleo, juntamente com isso a preocupação com a poluição ambiental e a emissão de gases de efeito estufa - GEE na atmosfera. Esses fatos fortalecem a importância da produção comercial dos biocombustíveis [22].

O presente trabalho tem como tema a Logística da Indústria de Biocombustível. Para compreender melhor o tema, a seguir serão descritos os conceitos acerca do assunto, bem como informações sobre esse tipo de combustível no Brasil e no mundo. Logística pode ser definida como todas as atividades de movimentação e armazenagem, que tornam o fluxo de produtos desde o ponto de aquisição da matéria-prima até ao ponto de consumo final mais facilitado, assim como dos fluxos de informação que colocam os produtos em movimento, com o propósito de providenciar níveis de serviço adequados aos clientes a um custo razoável [27].

Biocombustíveis são derivados de biomassa renovável, como cana-de-açúcar, oleaginosas, biomassa florestal e outras fontes de matéria orgânica, e podem substituir, parcial ou totalmente, combustíveis derivados de petróleo e gás natural em motores a combustão ou em outro tipo de geração de energia. Os biocombustíveis líquidos mais utilizados no Brasil são o etanol (álcool) obtido a partir de cana-de-açúcar e, em escala crescente, e o biodiesel, produzido a partir de óleos vegetais ou de gorduras animais, podendo serem aproveitados puros ou adicionado a combustível convencional. Comparados aos combustíveis fósseis (diesel e gasolina), os biocombustíveis são mais limpos, contribuindo para a redução das emissões de GEE em cerca de $90 \%$, e da poluição atmosférica nos centros urbanos [3].

Para transformar o cenário, em busca de uma redução significativa das emissões de dióxido de carbono, em longo prazo, os biocombustíveis poderão ter que exercer um papel de grande valor, segundo as análises da Agência Internacional de Energia - IEA [10]. É esperado um aumento de dez vezes na produção de biocombustíveis em 2050, como refere- 
se o documento Technology Roadmap - Biofuels for Transport, isso quer dizer que os biocombustíveis podem abastecer $25 \%$ de energia para o setor mundial dos transportes. Sendo assim, a substituição de combustíveis fósseis por biocombustíveis se tornará constante, no setor, que tem por base o petróleo fóssil.

Pensando no consumo de biocombustíveis no mundo, a América do Norte é atualmente o maior consumidor de biocombustíveis, seguida da América Latina, salientando a importância do Brasil, que é o segundo maior consumidor e também da União Europeia UE. Consoante com a IEA, há previsão de um aumento na procura de biocombustíveis, prevê-se que em 2030, os maiores consumidores continuem a serem os países da Organização de Cooperação e de Desenvolvimento Econômico - OCDE, os países da América do Norte e a UE, sendo responsáveis por cerca de $40 \%$ e $20 \%$, respectivamente. Ainda em 2030, estima-se que o consumo mundial de biocombustíveis chegue a $5 \%$ do volume total de combustível utilizado no setor dos transportes, fruto da implementação de políticas ambientais de combate às alterações climáticas, em particular no caso da UE em que foi fixado um objetivo de 10\% de energias renováveis neste setor para 2020 [10].

No Brasil, os combustíveis renováveis já representam 18\% dos combustíveis consumidos e cerca de $45 \%$ da energia já é renovável. Já no restante do mundo, $86 \%$ da energia derivam de fontes energéticas não renováveis [3]. O pioneirismo mundial no uso de biocombustíveis fez o Brasil atingir uma posição desejada por vários países que buscam desenvolver fontes renováveis de energia como alternativas estratégicas ao petróleo.

O governo sancionou uma lei $\left(\mathrm{n}^{0} 13.576 / 2017\right)$ em dezembro de 2017, que cria a RenovaBio, sigla para Política Nacional de Biocombustíveis, cujos objetivos são a contribuição para atender aos compromissos do Brasil no contexto do Acordo de Paris e também adequar relação de eficiência energética e de redução das emissões de GEE na produção, assim como na comercialização e no uso de biocombustíveis, até mesmo com mecanismos de avaliação de ciclo de vida, por entender a relevância de agregar valor à biomassa brasileira e o papel estratégico dos biocombustíveis na matriz energética nacional. Com plano de aumentar a participação da bioenergia na matriz energética brasileira, o governo pretende até 2030 ter um aumento de 18\%, levando em conta a meta de descarbonização para comercialização de combustíveis. Desta forma, esta nova política federal ajuda a fortalecer e refletir o atual cenário brasileiro dos biocombustíveis [31].

Para termos noção da relevância deste cenário no Brasil, a IEA estima para 2035 que se produza $200 \%$ a mais de biocombustíveis, um total de 4,1 milhões de barris, ou seja, 65 bilhões de litros. Projeta-se ainda que o Brasil assumirá $40 \%$ da exportação mundial de biocombustíveis. E assim, o governo brasileiro aposta na produção de biocombustíveis para atingir suas metas do Acordo de Paris, assim como conter os efeitos da mudança climática [31].

Visto a relevância de biocombustível para produção de novas formas de energias limpas, esse trabalho pretende responder a seguinte pergunta: qual o estado da arte sobre a temática da logística no âmbito da indústria de biocombustível? Com isso tem-se como objetivo do presente trabalho mapear o estado da arte sobre a temática da logística no âmbito da indústria de biocombustível, verificar quais as novas formas de matéria-prima que estão sendo estudadas e praticadas para a formação de novos tipos de biocombustíveis, assim como a otimização da cadeia logística dessa indústria. Após verificar o estado da arte sobre o tema, buscou-se realizar uma metassíntese ancorada em três parâmetros que serão explicados na seção correspondente.

Este estudo está organizado em seis seções. Estabelecido o marco introdutório, na sequência é apresentada a seção dois, onde é relatado o referencial teórico acerca da temática que trata da importância do estudo. A seção três descreve a metodologia utilizada no estudo. A seção quatro se refere à análise bibliométrica do portfólio obtido da pesquisa. A seção 
cinco apresenta uma metassíntese qualitativa desenvolvida com o portfólio, analisando três parâmetros para análise. E por último, na seção seis tem-se as considerações finais do estudo.

\section{REFERENCIAL TEÓRICO}

Os biocombustíveis vão se inserindo no mundo com no mínimo, uma dupla responsabilidade, ajudar a reduzir a emissão de GEE e substituir parcialmente o petróleo para alongar sua vida útil [22]. Dessa forma, percebe-se a importância dos biocombustíveis para o mundo, bem como todas as questões que envolvem sua logística.

A certeza de que o planeta necessita mais do que nunca, de biocombustíveis, são os seguintes fatos: recente divulgação do Painel Intergovernamental das Nações Unidas, que contemplam informações sobre as mudanças climáticas no mundo e o preço do petróleo sofrendo constantemente alterações [32]. Assim, confirma-se que a introdução dos biocombustíveis para substituição dos combustíveis fósseis é de extrema necessidade, visto que a preocupação ambiental é mundial e espera-se significativas mudanças nas formas de pensar e agir dos países, no que se refere a produção de energias limpas.

Atualmente, a produção mundial de biocombustíveis é baseada nas chamadas tecnologias de primeira geração, ou seja, produção de etanol a partir de açúcares ou amidos (cana, beterraba, milho, trigo, mandioca) e biodiesel de óleos vegetais ou gordura animal (soja, mamona, dendê, sebo, óleo de fritura). Para melhorar o quadro do desenvolvimento dos biocombustíveis, estão sendo desenvolvidas várias tecnologias que utilizam os materiais lignocelulósicos como matérias-primas (resíduos agroflorestais, madeira de florestas plantadas, culturas energéticas de curto ciclo, lixo urbano), estes são considerados mais baratos e abundantes, podendo ser produzidos nas mais variadas condições de solo e clima [22].

Além das plantas oleaginosas já citadas anteriormente, há outras plantas fornecedoras de óleo, como as nozes, avelãs e amêndoas, porém são cultivadas em menor escala. Existem algumas plantas oleaginosas que não tem finalidade de contribuir para a alimentação, é o caso do linho, da mamona e do pinhão-manso, e que fornecem óleo [8].

Um fator que a atividade de geração de energia propicia, através do uso dos biocombustíveis, é a abrangência social imposta à região produtora [8]. Comunidades de pequenos agricultores (agricultura familiar) são beneficiadas com a exploração dos produtos que abastecem essa indústria. Para exemplificar podemos citar a produção do biodiesel, as comunidades podem plantar os variados grãos oleaginosos, como a mamona, que pode ser explorada especialmente na região do semiárido nordestino, onde já está adaptada ao clima e ao solo.

A economia de energia se torna uma forma de reduzir os GEE, porém irá enfrentar algumas dificuldades, pois se necessita que se mude alguns hábitos, como o uso do veículo particular para transporte. Sendo assim, é de extrema necessidade o balanço energético da cadeia produtiva do biocombustível, assim como a quantidade de gases de efeito estufa emitidos na sua produção, incluindo as fases agrícola e industrial [22].

\section{METODOLOGIA}

Os procedimentos metodológicos deste trabalho serão apresentados quanto ao seu propósito, caráter, delineamento, método de coleta, análise dos dados e o tipo de revisão sistemática realizada. Quanto ao propósito, o trabalho se classifica como pesquisadiagnóstico. A pesquisa diagnóstica objetiva explorar o ambiente, de maneira a levantar e definir problemas [30]. No trabalho em questão, a pesquisa objetivou investigar a produção científica relacionada a biocombustíveis e sua respectiva logística. 
Quanto ao caráter, a pesquisa é classificada como quali-quantitativo. O caráter está ligado ao propósito do trabalho [30]. Como o propósito é alcançar uma quantidade de informações plausíveis acerca do assunto, através de buscas em bases de pesquisas e transformá-los em dados que serão analisados de forma estatística, se dá uma atenção maior a análise quantitativa.

O delineamento adotado para este trabalho é a pesquisa descritiva. O delineamento da pesquisa consiste em tornar o problema pesquisável, ou seja, vai determinar o que vai ser pesquisado e quais questões serão levantadas [30]. Dessa forma, o trabalho irá descrever as informações encontradas nos artigos de forma a identificar todas as suas características.

No que se refere ao método de coleta, foi utilizado a pesquisa em bases de dados, que possibilitou coletar e analisar as informações necessárias para o desenvolvimento deste trabalho. O tipo de dado que será coletado irá delimitar as possíveis formas de análise, podendo prever a utilização de gráficos, tabelas e estatísticas [30]. Para o autor é preciso pensar na análise, pois ela ajuda a decidir a forma como iremos coletar os dados, de forma mais crítica.

A metassíntese é definida como sendo a integração interpretativa de achados qualitativos (derivados de estudos fenomenológicos etnográficos, da teoria fundamentada dos dados e outros), que não a síntese interpretativa dos dados [24]. A autora afirma que uma interpretação dos resultados será produzida através das integrações realizadas, obtendo um nível teórico mais elevado, e que esta não é encontrada em nenhum dos estudos primários que foram analisados.

\section{ANÁLISE BIBLIOMÉTRICA}

Pesquisadores com formação em diversas áreas do conhecimento tem se apoderado da bibliometria, como forma de encontrar nesse método caminhos para a realização de "estados da arte" de suas áreas de conhecimento, da mesma forma mapear campos de pesquisa, produzir indicadores de produção científica e também analisar padrões de comunicação científica, por exemplo [34]. Para a realização desta etapa, o trabalho ocorreu da seguinte forma: primeiramente foi realizada a coleta de dados nas bases de pesquisa, e posteriormente a apresentação dos resultados desta análise.

\subsection{COLETA DE DADOS}

Foram realizadas as buscas em quatro bases de dados: Proquest, Science Direct, Scopus e Web Of Science. Foi descartada a utilização da plataforma CAPES, por resultar em números muitos grandes de resultados nas palavras-chave utilizadas, o mesmo aconteceu com o Google Scholar. Foi considerado o período aberto para todas as buscas.

Após, foi realizada a escolha das palavras-chave, sendo elas: Biofuels, Logistic chain, Supply chain, Logistics, Renewable fuel, Alternative fuel, Biofuels production, Biological fuel, Supply chain management e Energy planning.

No início da pesquisa, considerando as combinações dessas palavras-chave, foi coletado um total de 6.892 documentos, já com os documentos duplicados excluídos como primeira etapa de filtragem.

Continuando a filtragem, foi feita a exclusão dos documentos que não se enquadraram em Journal article. A partir disso, começou-se a eliminação dos artigos que não estavam alinhados com o trabalho através da leitura dos títulos, restando 1.170 artigos.

Seguindo a filtragem, os artigos foram analisados através de suas palavras-chave e foram excluídos aqueles que apresentavam desalinhamento com a pesquisa, o mesmo aconteceu após a leitura dos resumos dos artigos, para verificar quais artigos estavam alinhados. Obteve-se um total de 126 artigos. Após verificar os artigos que estavam acessíveis em seu texto integral, ficou-se com um total de 115 artigos, definindo, assim, o 
portfólio. Na Tabela 1, está organizada por base de dados a distribuição do portfólio.

Tabela 1 - Quantidade de artigos por base de dados

\begin{tabular}{cc}
\hline Bases de dados & Número de artigos \\
\hline Proquest & 2 \\
Science Direct & 9 \\
Scopus & 41 \\
Web Of Science & 63 \\
\hline
\end{tabular}

Fonte: Dados de pesquisa.

\subsection{RESULTADOS DA BIBLIOMETRIA}

Nesta etapa serão demonstrados todos os resultados da bibliometria, contando com análises correspondentes à produção e autoria, conteúdo e citação dos artigos.

Primeiramente analisou-se o ano de publicação de cada artigo. A pesquisa foi realizada no primeiro semestre de 2018 e resultou em uma abrangência de 2007 até o período pesquisado. Percebe-se que o ano de maior produção no assunto da logística dos biocombustíveis foi o ano de 2016 com 25 artigos publicados, como mostra a Fig. 1.

Figura 1 - Número de publicações por ano

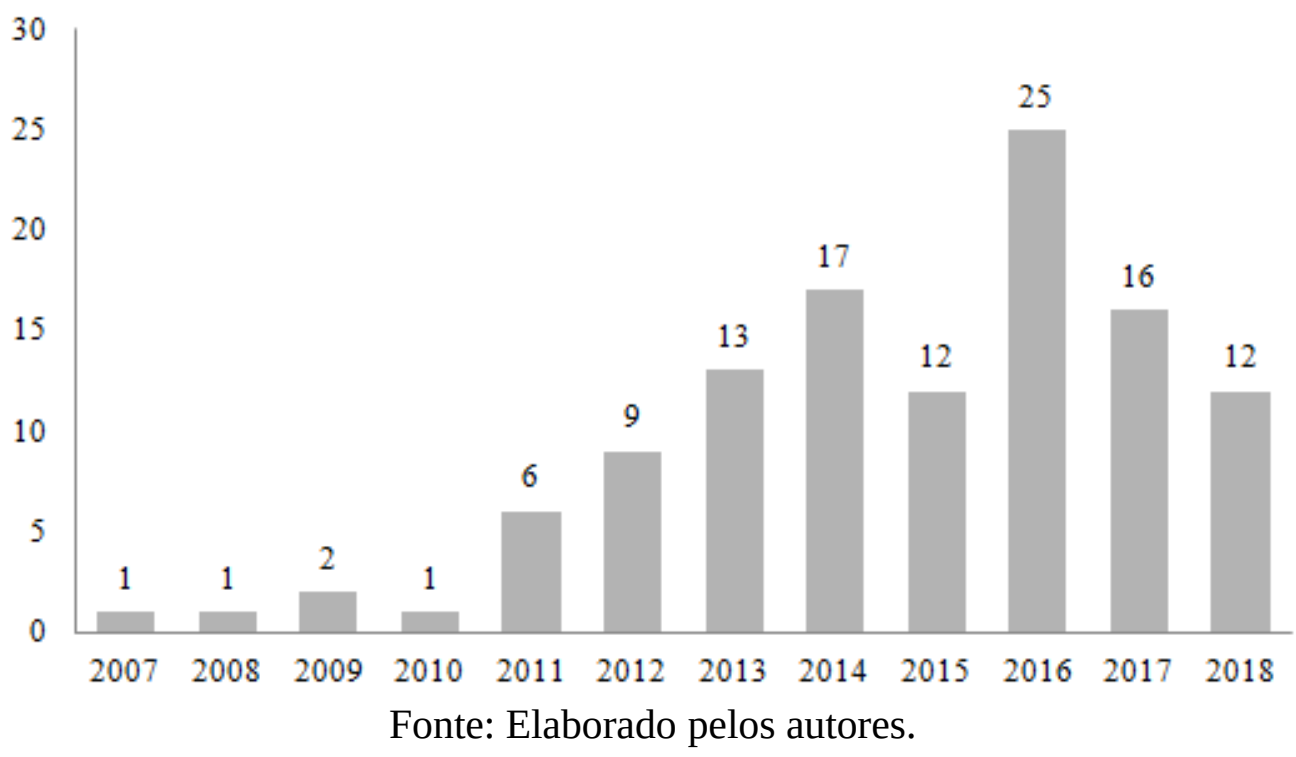

Analisou-se os autores que tiveram a maior participação na pesquisa. As referências no assunto foram os autores Nilay Shah, Fabrizio Bezzo e Luiz Rodríguez, que representaram um total de seis artigos publicados por cada um. Tiveram-se seis autores que publicaram quatro artigos cada e 16 autores publicaram três artigos cada.

Também foram analisadas quais as universidades que tiveram o maior número de participação. Ênfase para as universidades Iran University of Science and Technology e University of Illinois at Urbana-Champaign, com um total de seis participações cada, seguido das universidades Iowa State University e University of Tennessee com quatro artigos publicados cada.

A seguir, elencou-se os países com maior número de participação. Destacou-se os Estados Unidos, que teve um total de 51 participações, seguido do Irã que teve 12 artigos publicados. A China ficou em terceiro lugar com nove participações e a Itália contou com cinco artigos publicados. 
A seguir, listou-se as palavras-chave mais utilizadas nos artigos. Destaque para a palavra-chave Supply chain, que apareceu 22 vezes, a palavra Optimization foi utilizada 20 vezes, Biomass também teve grande relevância, aparecendo 18 vezes, assim como Sustainability e Biofuel que foram utilizadas 13 vezes.

Analisando o número de autores por artigo, verificou-se que 38,2\% do portfólio foi realizado por três autores, $18,2 \%$ por dois autores, $13,9 \%$ por quatro autores e $12,1 \%$ por cinco autores.

Foi analisada a quantidade de vezes que os artigos foram citados. O artigo mais citado foi Biomass-to-bioenergy and biofuel supply chain optimization: Overview, key issues and challenges, com um total de 426 citações. Esta análise foi realizada no site Google Scholar no mês de Agosto de 2019.

\section{METASSÍNTESE}

A metassíntese qualitativa do estudo visa promover a apresentação das contribuições dos artigos do portfólio bibliográfico. Para isso, buscou-se estabelecer alguns parâmetros sobre a temática de pesquisa a fim de ter uma orientação para guiar as análises. Assim, foi estipulado um total de três parâmetros relacionados à cadeia logística dos biocombustíveis. Os parâmetros que darão suporte para uma avaliação do que foi produzido na área são os seguintes: modal de transporte, geográfico e produção. Esses parâmetros foram selecionados após leitura completa dos artigos do portfólio, garantindo dessa forma estarem presentes em grande parte do portfólio.

O parâmetro modal de transporte vai identificar quais tipos de modais estão sendo utilizados para transportar tanto a matéria-prima, que é utilizada para a transformação do biocombustível, quanto o produto final (biodiesel, bioetanol, biogás). O parâmetro geográfico diz respeito a oferta e demanda, que são as informações para conhecer o estado do mercado, e a posição geográfica que está sendo realizado o estudo. O parâmetro produção irá identificar as matérias-primas utilizadas e o tipo de processo/tecnologia que envolve a produção dos biocombustíveis.

\subsection{RESULTADOS E DISCUSSÃO}

Para dar início ao levantamento dos artigos que abrangem os parâmetros, é preciso destacar que um total de 26 artigos não contemplavam os parâmetros propostos, ficando de fora da análise. Desta forma, os levantamentos se deram referente aos 89 artigos restantes.

Analisando a quantidade de artigos que identificaram os três parâmetros no estudo, tem-se um total de 46 artigos. Houveram artigos em que foi identificado somente dois parâmetros no estudo, sendo a maior quantidade do portfólio, levando em conta somente os parâmetros geográfico e produção, correspondendo a um total de 39 artigos. Esse levantamento pode ser melhor visualizado a seguir, na Tabela 2.

Tabela 2 - Representatividade quantitativa da amostra por parâmetros

\begin{tabular}{ccc}
\hline Parâmetros & Quantidade de artigos & $\mathbf{\%}$ \\
\hline Modal, Geográfico e Produção & 46 & $51,68 \%$ \\
Geográfico e Produção & 39 & $43,82 \%$ \\
Modal e Produção & 1 & $1,12 \%$ \\
Modal e Geográfico & 1 & $1,12 \%$ \\
Modal & 1 & $1,12 \%$ \\
Produção & 1 & $1,12 \%$ \\
TOTAL & 89 & $100 \%$ \\
\hline
\end{tabular}

Fonte: Dados de pesquisa. 
Os biocombustíveis são classificados em dois tipos: os biocombustíveis de primeira e segunda geração. Os biocombustíveis que se enquadram na classificação de primeira geração são aqueles produzidos a partir de culturas agrícolas, como milho e cana-de-açúcar. Podem ser usados pela indústria de alimentos e forragem, ocasionando possíveis problemas sociais, insegurança alimentar, aumento dos preços dos alimentos, justificado por usarem recursos como a terra, assim como culturas comestíveis, distante da indústria alimentícia gerando uma concorrência travada com o setor de alimentos [2; 11; 36]. Os biocombustíveis do tipo segunda geração são produzidos a partir de biomassa lignocelulósica, que são fontes não comestíveis, como resíduos de colheitas e florestais e culturas energéticas, como Switchgrass [26].

Os efeitos das questões levantadas anteriormente, causados pelos biocombustíveis de primeira geração, tem estimulado o interesse pelos biocombustíveis de segunda geração, e o seu uso pode resolver esses problemas [15; 35]. Porém, há ainda grandes barreiras que dificultam a produção comercial no curto e médio prazo, que se referem aos custos de capital e custos operacionais [28].

Em busca de combustíveis líquidos que sejam mais sustentáveis, muitos países se preocuparam em dedicar-se em soluções mais vantajosas. O bioetanol de milho, como se pensava até pouco tempo atrás, era visto como a melhor solução no setor de transporte. Porém, o que está se destacando em termos de longo prazo, é o etanol celulósico, com sua maior capacidade em relação à primeira geração [16]. Muitas regiões possuem grande potencial para gerar biocombustível desse tipo, é o caso do Paquistão, utilizando resíduos de milho, do Texas com vários tipos de matérias primas celulósicas disponíveis, como gramíneas, resíduos de moinhos e resíduos de madeira urbanos [2; 12]. A palha de milho se destaca nos estados do Meio-Oeste dos Estados Unidos, especialmente em Lowa, sendo a matéria-prima principal para a produção de bicombustíveis de segunda geração [40]. Na Califórnia, se encontra em abundância resíduos de biomassa, como a palha de milho e resíduos florestais propiciando o desenvolvimento da indústria de biocombustível celulósico [18].

Existem diversas matérias-primas celulósicas disponíveis para a produção de bicombustíveis de segunda geração, uma delas é conhecida pelo seu alto teor de biomassa, o Switchgrass, um capim nativo dos Estados Unidos que tem uma grande vantagem se comparado com outras matérias-primas, pelo fato de ser altamente adaptável a diversas condições de solo e por sua natureza benéfica ao meio ambiente [29]. Miscanthus é uma cultura de energia de segunda geração de grande potencial, pois tem um alto rendimento de cultivo e comparando com a cana-de-açúcar tem uma maior eficiência de conversão em etanol [1]. Jatropha, mais conhecida como pinhão manso, é um arbusto durável, sua média de vida é de 30 a 50 anos e conta com uma altura média de $5 \mathrm{~m}$, podendo crescer até $10 \mathrm{~m}$. Se cultivada em pousio com plantações em fileiras, pode eliminar o carbono no solo [7]. Considerada uma matéria-prima de biocombustível, Jatropha é muito promissora devido às suas características de compatibilidade com diferentes tipos de terra, como regiões áridas e semi-áridas. Essa matéria-prima se torna importante principalmente no Irã, pois a metade sul do país é adequada para o seu cultivo propiciando a produção futura de biodiesel [13]. Na Índia, a Jatropha também é de grande importância para a produção de biocombustível, pois lá a demanda por diesel é cinco vezes maior que a demanda de gasolina [17].

Um estudo apresentou uma estrutura de modelagem estática multiobjetiva, ou seja, buscou um equilíbrio entre os objetivos econômico e ambiental, para a otimização de cadeias de fornecimento de biocombustíveis híbridos de primeira/segunda geração. Neste estudo foi analisado a produção de bioetanol utilizando trigo e palha de trigo no Reino Unido, porém assumiu-se que as culturas energéticas especiais poderão ser utilizadas somente após 2020, 
que é a estimativa de quando ficarão prontas [1]. A tecnologia híbrida para produção de biocombustíveis deve ser utilizada para reduzir as emissões de GEE, e dessa forma atingir as metas dos países. Essa constatação se dá pelo resultado obtido no estudo intitulado Spatially explicit multi-objective optimization for design and planning of hybrid first and second generation biorefineries dos autores Sara Giarola, Andrea Zamboni e Fabrizio Bezzo, quando apresentam um modelo de otimização multiobjetivo para o projeto e planejamento ideal de biorrefinarias híbridas de primeira e segunda geração.

A indústria de biocombustíveis enfrenta muitos desafios, um deles são as tecnologias alternativas utilizadas para converter a biomassa de lignocelulose em biocombustível. Essas tecnologias podem ser bioquímicas, como a hidrólise enzimática, a conversão ainda pode se dar por meio de processos termoquímicos, como a explosão de vapor e pirólise, e há também a possibilidade de converter as matérias-primas por processos bio-termoquímicos, por via de carboxilato. Pensando em melhorar as técnicas dos processos de conversão, criou-se um modelo de simulação que visou estudar como se dá o processo de geração de biogás via silagem de gramíneas [20]. Este estudo se baseou no modelo número um da Digestão Anaeróbia da International Water Association, que se utiliza de processos químicos altamente complexos. Para analisar as cadeias de valor alternativas específicas para produzir biocombustíveis avançados via tecnologia de pirólise rápida, precisou-se buscar informações sobre a composição do óleo de pirólise, para isso o óleo foi produzido em equipamentos de laboratório e hidrotratado para reduzir o nível de oxigênio. A remoção de oxigênio corresponde o maior custo no processo de conversão da biomassa para biocombustível, visando buscar economia nesse processo, um modelo foi criado afirmando que a remoção de oxigênio deve ser realizada na unidade de hidroprocessamento, e gerenciado por toda a cadeia de valor, assim se o oxigênio puder ser eliminado no projeto de cultura de energia, na unidade de pirólise ou refinaria poderá contribuir para economias substanciais [4].

A indústria de biocombustíveis de segunda geração precisa ainda de avanços tecnológicos significativos para se desenvolver com foco em redução nos custos [15]. A nova tecnologia avançada de conversão de biocombustível é o etanol de lignocelulose via hidrólise, que utiliza tecnologia de conversão de fermentação com um processo de prétratamento usando ácido diluído. O processo ácido diluído se destaca por apresentar um baixo custo de enzimas de celulose e um rendimento significativo de etanol, sendo considerado a tecnologia mais promissora atualmente [19; 21]. A biomassa altamente densificada pode trazer resultados consideráveis em se tratando de eficiência de conversão, de modo que se possa ter tamanhos de partículas mais finas e superfície de reação aumentada. Dessa forma, interferiria no desempenho total do sistema assim como nas decisões que permeiam a escolha da tecnologia utilizada [23].

Outro ponto a ser analisado neste estudo foi as informações de demanda e oferta dos biocombustíveis nos locais de estudos dos artigos. A indústria de biocombustíveis enfrenta inúmeras incertezas, e uma delas é a demanda. A demanda muitas vezes pode ser obtida com base em metas de bicombustíveis para um determinado período de tempo e também calculada de acordo com a demanda atual total de gasolina, número registrado de veículos e a população do local de estudo. A demanda total pode ser distribuída entre o número de centros de demanda da região, que correspondem aos depósitos internos [39]. O ambiente de mercado é o fator principal para identificar o estado de demanda do local, assim destaca-se uma das contribuições do modelo desenvolvido no estudo intitulado A mathematical model to design a lignocellulosic biofuel supply chain system with a case study based on a region in Central Texas dos autores Heungjo An, Wilbert Wilhelm e Stephen Searcy, que auxilia no nível tático, e um dos pontos principais são as previsões mais precisas de demanda, que estão disponíveis para planejar questões específicas da cadeia logística. Os autores analisaram o 
custo do Switchgrass versus o preço do Etanol em dezoito cenários, e em três cenários avaliaram oferta versus demanda. A oferta pode ser calculada segundo informações do Departamento de Agricultura dos Estados Unidos - USDA para tal, que será de acordo com a quantidade de resíduos de culturas disponíveis no local analisado, levando em conta a área de terra cultivada assim como o rendimento da cultura. Constata-se que o governo tem papel importante em se tratando de influência no nível de demanda, como foi no caso do Irã, em que a publicidade realizada pelo governo Iraniano em prol do uso de biocombustíveis ocasionou um aumento na demanda por biodiesel. Com essa situação, a importação pode ser a saída para fornecer o biodiesel necessário para atender a demanda no Irã [5].

Outro fator a ser considerado na cadeia logística dos biocombustíveis são os modais de transporte. A escolha pelo transporte rodoviário está associada muitas vezes pela limitada acessibilidade das matérias-primas, no caso de regiões florestais, o que implica na falta de opções, sendo este modal a única solução viável de transporte [6]. Buscando diminuir os custos de transporte e também facilitar a liberação de suprimentos de biomassa que estão distantes, foi analisado as redes de transporte intermodal. Essas redes baseiam-se em múltiplos modos de transporte, podendo abranger o rodoviário, ferroviário e fluvial/marítimo. Constatou-se que o transporte intermodal é satisfatório nos percursos de grandes distâncias na medida em que proporciona uma economia nos custos [33; 9]. Analisando a escolha do modal de transporte em termos de densidade e quantidade dos materiais que serão transportados, o rodoviário é preferido para produtos de alta densidade, considerando a melhor opção de transporte para o etanol. Porém, quando se precisa transportar grandes quantidades, a melhor escolha é o modal ferroviário, como no caso do milho, nos campos de cultivo até as plantas de produção, ou do etanol, quando levado das plantas para os nós de distribuição [39]. Os transportes rodoviário e ferroviário são considerados os principais métodos para transportar as matérias-primas de biomassa celulósica. O que vai implicar na escolha do melhor modal de transporte é a capacidade de volume e de peso [37]. O transporte dutoviário é considerado o mais econômico no longo prazo, porém a sua desvantagem são os custos iniciais [38]. Esse modal de transporte é escolhido quando se tem um alto volume e precisa-se enviar o lodo por longas distâncias. Assim, o transporte do lodo é de grande importância para a cadeia de suprimento, transportando um alto volume e assim garantindo a produção do biocrude na usina [25].

Após análise dos estudos, foi elaborado um mapa-múndi ilustrando a matéria-prima mais utilizada, assim como a mais promissora de cada região. Para isso, analisou-se as informações mais recentes das regiões estudadas. Essa forma de demonstrar ilustrativamente foi escolhida devido à grande variedade de matérias-primas encontradas em diferentes regiões do mundo, dificultando uma análise territorial por continentes, como foi a ideia inicial. Dessa forma pode-se ter uma visão geral no contexto mundial, com uma visualização mais adequada e informativa possível, como mostra a Fig. 2. 
Figura 2 - Ilustração do mapa-múndi com as matérias-primas

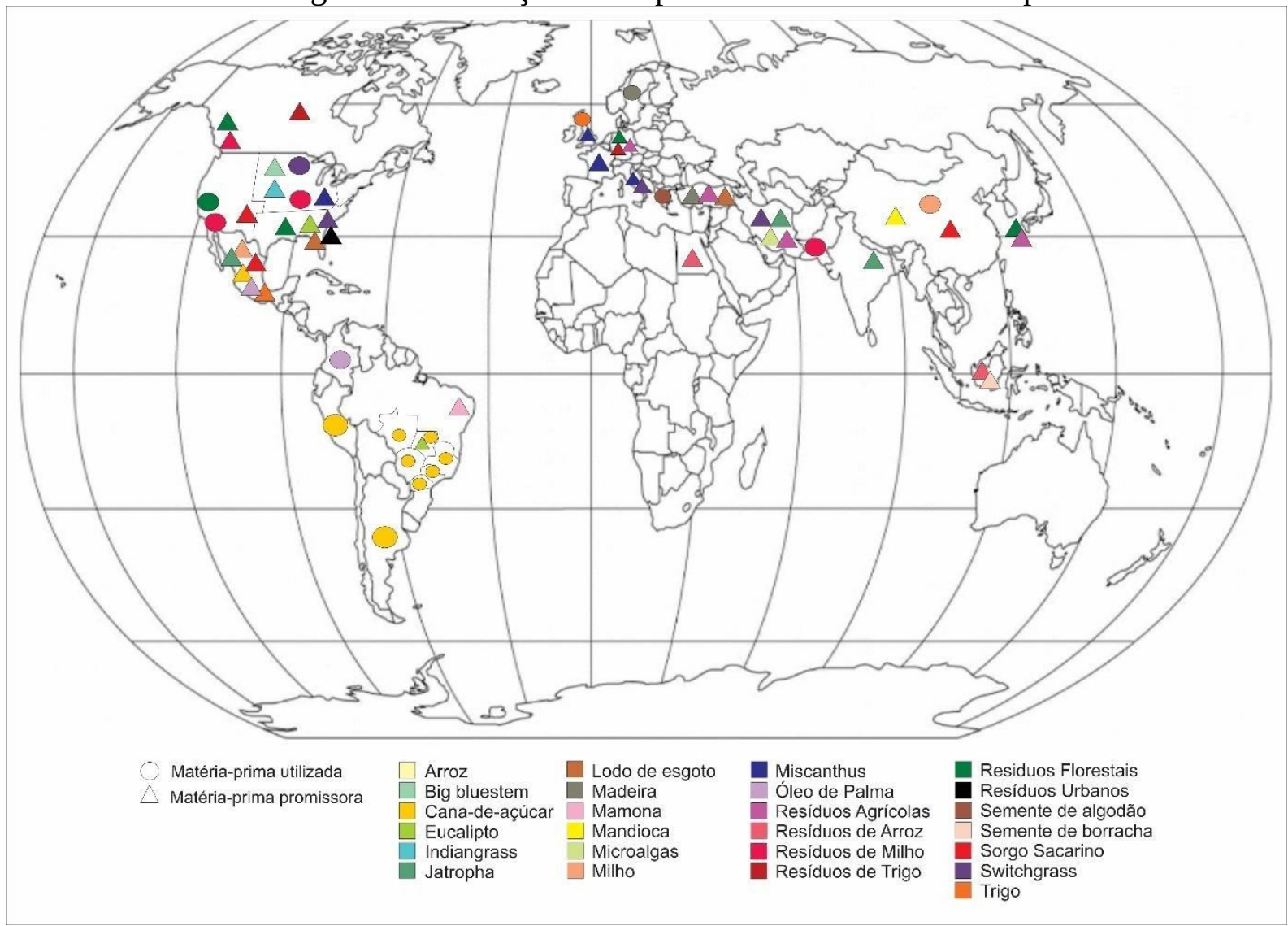

Fonte: Elaborado pelos autores.

\section{CONSIDERAÇÕES FINAIS}

O presente trabalho teve o objetivo de mapear o estado de arte sobre a temática da logística no âmbito da indústria de biocombustível, através de uma extensa análise bibliométrica para que pudesse alimentar as necessidades principais do trabalho. Foi realizada a coleta e análise dos dados e descrito os resultados, sendo encontrado um número considerável de artigos alinhados ao assunto, com um total de 115 artigos, isso demonstra que o tema não é limitado.

Pode-se destacar que a produção científica no que se refere à logística de biocombustíveis é um tema atual, visto que a pesquisa mostrou resultados nos últimos dez anos, com um aumento da produção nos últimos cinco anos, de 2013 a 2018. No que se refere a limitação da pesquisa, pode-se ressaltar que houve uma indisponibilidade de 11 artigos na íntegra. Com isso, não se pode ter acesso ao conteúdo desses artigos que estavam alinhados com o tema de pesquisa.

Após realização da bibliometria, que objetivou levantar as características principais do portfólio, foi elaborada uma metassíntese, analisando 89 artigos. Com a realização da metassíntese, pode-se chegar a algumas conclusões. O surgimento dos biocombustíveis é explicado por ser uma alternativa que é renovável e dessa forma atraente para satisfazer as demandas globais no que diz respeito as formas de geração de energia de transporte sustentável.

As matérias-primas, principalmente resíduos agrícolas, culturas energéticas e material lenhoso se destacam devido aos ganhos que eles podem trazer, como independência energética, mitigação das mudanças climáticas e desenvolvimento econômico rural. 
Contudo, essas matérias-primas estão amplamente distribuídas geograficamente, e isso requer que o transporte seja eficiente e eficaz, fator crítico no que se refere a produção de biocombustível celulósico, principalmente em grande escala.

Vários estudos mostram como a escolha da matéria-prima impacta no crescimento econômico, na proteção ecológica e a busca por uma cadeia de fornecimento socialmente responsável. A maioria dos estudos que tratavam do modal de transporte, enfatizavam o uso preferencialmente pelo modal rodoviário seguidamente pelo modal ferroviário. Pode-se afirmar que o transporte geralmente acontece nas estradas, assim o cenário é de más estruturas rodoviárias, o que acaba acarretando um custo maior no transporte.

Os primeiros estudos sobre a cadeia de suprimentos de biocombustível buscavam melhores resultados econômicos, desconsiderando os aspectos ambientais. Entretanto, atualmente, pesquisadores estão se comprometendo a estudar modelos multi-objetivos. Um foco de estudo é a técnica Avaliação do Ciclo de Vida, que avalia o impacto de um produto no meio ambiente ao longo do seu ciclo de vida.

Portanto, o trabalho busca chamar a atenção para o tema que é considerado significativo no que se refere à manutenção de um planeta mais limpo energeticamente. Observa-se que há necessidade de novos estudos no tema, para que se possa ter escolhas confiáveis para o desenvolvimento de uma cadeia logística que leve em conta fatores econômicos, sociais e ambientais, otimização e melhorando a gestão.

\section{REFERÊNCIAS BIBLIOGRÁFICAS}

[1] AKGUL, O.; SHAH, N.; PAPAGEORGIOU, L. G. An optimisation framework for a hybrid first/second generation bioethanol supply chain. Computers \& Chemical Engineering, v. 42, p. 101-114, 2012.

[2] AN, H.; WILHELM, W. E.; SEARCY, S. W. A mathematical model to design a lignocellulosic biofuel supply chain system with a case study based on a region in Central Texas. Bioresource technology, v. 102, n. 17, p. 7860-7870, 2011.

[3] ANP, 2018. Informações. Disponível em: <http://www.anp.gov.br/biocombustiveis>. Acesso em: 28 mar. 2018.

[4] ARBOGAST, S.; BELLMAN, D.; PAYNTER, J. D.; WYKOWSKI, J. Advanced biofuels from pyrolysis oil: The impact of economies of scale and use of existing logistic and processing capabilities. Fuel processing technology, v. 104, p. 121-127, 2012.

[5] AZADEH, A.; ARANI, H. V. Biodiesel supply chain optimization via a hybrid system dynamics-mathematical programming approach. Renewable energy, v. 93, p. 383403, 2016.

[6] BA, B. H.; PRINS, C.; PRODHON, C. A generic tactical planning model to supply a biorefinery with biomass. Pesquisa Operacional, v. 38, n. 1, p. 1-30, 2018.

[7] CHERUBINI, F.; BIRD, N.; COWIE, A.; JUNGMEIER, G.; SCHLAMADINGER, B.; Gallasch, S. Energy- and greenhouse gas-based LCA of biofuel and bioenergy systems: Key issues, ranges and recommendations. Resources, Conservation and Recycling, v. 53, n. 8, p. 434-447, 2009.

[8] DONATO, V. Logística para a Indústria do Petróleo, Gás e Biocombustíveis. São Paulo: Ética Ltda. 2012. 
[9] EKSIOGLU, S.; LI, S.; ZHANG, S.; SOKHANSANJ, S.; PETROLIA, D. Analyzing impact of intermodal facilities on design and management of biofuel supply chain. Transportation Research Record, v. 2191, n. 1, p. 144-151, 2010.

[10] ENMC. Informações. Disponível em: <http://www.enmc.pt/pt-PT/atividades/biocombustiveis/benchmarking/ > Acesso em: 22 abr. 2018.

[11] FRITSCHE, U. HÜNECKE, K.; HERMANN, A.; SCHULZE, F.; WIEGMANN, K. Sustainability Standards for Bioenergy, Frankfurt a. M.: WWF Germany, 2006.

[12] GHAFOOR, A.; REHMAN, T.; MUNIR, A.; AHMAD, M.; IQBAL, M. Current status and overview of renewable energy potential in Pakistan for continuous energy sustainability. Renewable and Sustainable Energy Reviews, v. 60, p. 1332-1342, 2016.

[13] GHELICHI, Z.; SAIDI-MEHRABAD, M.; PISHVAEE, M. S. A stochastic programming approach toward optimal design and planning of an integrated green biodiesel supply chain network under uncertainty: A case study. Energy, v. 156, p. 661-687, 2018.

[14] GIAROLA, S.; ZAMBONI, A.; BEZZO, F. Spatially explicit multi-objective optimization for design and planning of hybrid first and second generation biorefineries. Computers \& Chemical Engineering, v. 35, n. 9, p. 1782-1797, 2011.

[15] GIAROLA, S.; BEZZO, F.; SHAH, N. A risk management approach to the economic and environmental strategic design of ethanol supply chains. Biomass and bioenergy, v. 58, p. 31-51, 2013.

[16] GIAROLA, S.; ZAMBONI, A.; BEZZO, F. Environmentally conscious capacity planning and technology selection for bioethanol supply chains. Renewable Energy, v. 43, p. 61-72, 2012.

[17] GOSWAMI, K.; HAZARIKA, A. Supply chain network of Jatropha based biodiesel industry in North East India. Sustainable Production and Consumption, v. 6, p. 3850, 2016.

[18] HUANG, Y.; CHEN, Y. Analysis of an imperfectly competitive cellulosic biofuel supply chain. Transportation Research Part E, v. 72, p. 1-14, 2014.

[19] HUANG, Y.; FAN, Y.; CHEN, C. An integrated biofuel supply chain to cope with feedstock seasonality and uncertainty. Transportation Science, v. 48, n. 4, p. 540554, 2014.

[20] KOCH, K.; LÜBKEN, M.; GEHRING, T.; WICHERN, M.; HORN, H. Biogas from grass silage - Measurements and modeling with ADM1. Bioresource Technology, v. 101, n. 21, p. 8158-8165, 2010.

[21] LEBOREIRO, J.; HILALY, A. K. Analysis of supply chain, scale factor, and optimum plant capacity for the production of ethanol from corn stover. Biomass and bioenergy, v. 54, p. 158-169, 2013.

[22] LEITE, R. C. C.; LEAL, M. R. O biocombustível no Brasil. Novos estud.- CEBRAP, São Paulo, n. 78, p. 15-21, 2007.

[23] LIN, T.; RODRÍGUEZ, L. F.; DAVIS, S.; KHANNA, M.; SHASTRI, Y.; GRIFT, T.; LONG, S.; TING, K. C. Biomass feedstock preprocessing and long-distance transportation logistics. Gcb Bioenergy, v. 8, n. 1, p. 160-170, 2016. 
[24] MATHEUS, M. C. C. Metassíntese qualitativa: desenvolvimento e contribuições para a prática baseada em evidências. Acta Paulista de Enfermagem, v. 22, n. spe2, p. 543-545, 2009.

[25] MARUFUZZAMAN, M.; EKŞIOĞLU, S. D.; HERNANDEZ, R. Environmentally friendly supply chain planning and design for biodiesel production via wastewater sludge. Transportation Science, v. 48, n. 4, p. 555-574, 2014.

[26] MEMIŞOĞLU, G.; ÜSTER, H. Integrated bioenergy supply chain network planning problem. Transportation Science, v. 50, n. 1, p. 35-56, 2015.

[27] MOURA, B. Logística: Conceito e Tendências. Centro Atlântico: Lisboa, 2006.

[28] PICCOLO, C.; BEZZO, F. A techno-economic comparison between two technologies for bioethanol production from lignocelluloses. Biomass Bioenergy, v. 33, n. 3, p. 478-491, 2009.

[29] RINEHART, L. Switchgrass as a bioenergy crop. National Center for Appropriate Technology, 2006.

[30] ROESCH, S. M. A. Projetos de estágio e de pesquisa em administração: guia para estágios, trabalhos de conclusão, dissertações e estudos de caso. $3^{\text {a }}$ ed. São Paulo: Atlas, 2015.

[31] SASSON, J. M. Breves considerações sobre a RenovaBio e o cenário brasileiro de Biocombustíveis. Portal Direito Ambiental, 2018. Disponível em:

$<$ http://direitoambiental.com/breves-consideracoes-sobre-a-renovabio-e-o-cenariobrasileiro-de-biocombustiveis/>. Acesso em: 12 abr. 2018.

[32] SAUER, I. Biocombustíveis no Brasil: comercialização e logística. In: BRASIL. Ministério das relações exteriores - MRE (Org.). Biocombustíveis no Brasil: realidades e perspectivas. Brasília: Arte Impressora Gráfica LTDA, 2007. Disponível em: <https://sistemas.mre.gov.br/kitweb/datafiles/NovaDelhi/pt-br/file/ Biocombustiveis_03-biocombustiveisnobrasil.pdf>. Acesso em: 13 abr. 2019.

[33] SEARCY, E.; FLYNN, P.; GHAFOORI, E.; KUMAR, A. The relative cost of biomass energy transport. Appl Biochem Biotechnol, v. 137-140, n. 1-12, p. 639-652, 2007.

[34] SILVA, M. R.; HAYASHI, C. R. M.; HAYASHI, M. C. P. I. Análise bibliométrica e cientométrica: desafios para especialistas que atuam no campo. InCID: Revista de Ciência da Informação e Documentação, Ribeirão Preto, v. 2, n. 1, p. 110-129, jun, 2011.

[35] SIMS, R.; TAYLOR, M.; SADDLER, J.; MABEE, W. From 1st- to 2nd-generation biofuel technologies. Paris: International Energy Agency (IEA) and Organisation for Economic Co-Operation and Development, 2008.

[36] SINGH, A.; PANT, D.; KORRES, N.; NIZAMI, A.-S.; PRASAD, S.; MURPHY, J. Key issues in life cycle assessment of ethanol production from lignocellulosic biomass: Challenges and perspectives. Bioresource Technology, v. 101, n. 13, p. 5003-5012, 2010.

[37] YOU, F.; TAO, L.; GRAZIANO, D. J.; SNYDER, S. W. Optimal design of sustainable cellulosic biofuel supply chains: multiobjective optimization coupled with life cycle assessment and input-output analysis. AIChE Journal, v. 58, n. 4, p. 11571180, 2012. 
[38] YUE, D.; YOU, F..; SNYDER, S. Biomass-to-bioenergy and biofuel supply chain optimization: overview, key issues and challenges. Computers \& Chemical Engineering, v. 66, p. 36-56, 2014.

[39] ZAMBONI, A.; SHAH, N.; BEZZO, F. Spatially explicit static model for the strategic design of future bioethanol production systems. 1. Cost minimization. Energy \& Fuels, v. 23, n. 10, p. 5121-5133, 2009.

[40] ZHANG, L.; HU, G. Supply chain design and operational planning models for biomass to drop-in fuel production. Biomass and bioenergy, v. 58, p. 238-250, 2013. 